Vesna Ristanović ${ }^{1}$, Roksanda Stojanović

\title{
ANALIZA INDEKSA AKTIVNOSTI ECLAM I INDEKSA OŠTEĆENJA DAMAGE KOD BOLESNIKA SA SLE U ZDRAVSTVENOM CENTRU UŽICE
}

\begin{abstract}
Apstrakt: Sistemski eritemski lupus (SLE) je autoimuna bolest koja se karakteriše multisistemskim ispoljavanjem i serološkim nalazom mnogobrojnih autoantitela. Svaki organ može biti zahvaćen: koža, zglobovi, seroze: pleura, perikard, peritoneum, bubrezi, CNS i hematopoezno tkivo. U etiopatogenezi bolesti, pored genetske predispozicije, važnu ulogu igraju hormonski činioci i spoljašnji etiološki faktori. Uzajamnim dejstvom pokreće se sistem autoimunosti sa hiperreaktivnošću B limfocita koji produkuju autoantitela, najznačajnija su ANA At koja sa Ag grade imune komplekse koji se talože i aktiviraju sistem komplementa i započinju proces zapaljenja i oštećenja različitih tkiva i organa.

Cilj rada je analiza kliničkih manifestacija SEL u različitim fazama aktivnosti bolesti procenjivano ECLAM testom, kao i stepen oštećenja organa, ispitivanje terapijskog pristupa i toka bolesti i ispitivanje ishoda SEL kod bolesnika registrovanih u Zlatiborskom regionu. Ispitivanje je sprovedeno u vidu retrospektivne studije i studije preseka. Obuhvaćeno je 60 bolesnika, izvori podataka su ambulantni i hospitalni registri bolesnika sa SEL lečenih u ZC Užice i referentnim ustanovama u Beogradu. Upitnik je imao 175 pitanja, korišćen je INDEX aktivnosti ECLAM i INDEX oštećenja SLICC/ACR DAMAGE INDEX.
\end{abstract}

Ključne reči: sistemski eritemski lupus, Eclam, Damage index.

\section{Uvod}

Indeks aktivnosti ECLAM (European Consensus Lupus Activity Measurement) je upitnik kojim se procenjuje aktivnost bolesti na osnovu broja sabranih bodova. Sadrži 12 stavki:

1. Opšte pojave, temperatura, zamor broj poena

2. Zglobne pojave, artritis, nova artralgija 
3/a. Eritem obraza ili genarilozava ospa...

$$
0,5
$$

$3 /$ b. nove mukokutane pojave

4. Miozitis **

5. Perikarditis

\section{2}

6. Crevne manifestacije

7. Pleuritis/pneumonitis

8. Glavobolja/migrena, Epi, CVI **

9. Bubrežne manifestacije ** 2

$9 /$ b. Nove bubrežne promene 0,5

10. Hematološke pojave *

11. Ubrzana SE

12. Hipokomplementemia $\mathrm{C} 3$ ili $\mathrm{CH} 50$

12/b. Nova hipokomplementemia

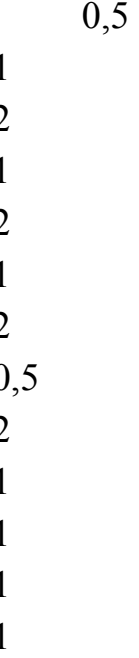

** ako je ova manifestacija ili sistem jedini zahvaćen, dodati još 2 poena

Svim bolesnicama određena je vrednost ECLAM-a i DAMAGE:

\begin{tabular}{|c|c|c|c|}
\hline ECLAM vr. br. & bol. (\%) & DAMAGE & vr. br. bol. $(\%)$ \\
\hline 1 & $6(10)$ & 0 & $10(17)$ \\
\hline 2 & $12(20)$ & 1 & $26(43)$ \\
\hline 3 & $20(33)$ & 2 & $13(22)$ \\
\hline 4 & $7(12)$ & & \\
\hline 3 & $4(7)$ & & \\
\hline 5 & $9(16)$ & 4 & $2(3)$ \\
\hline 6 & $3(6)$ & 5 & $2(3)$ \\
\hline 7 & $2(3)$ & 7 & $3(6)$ \\
\hline 8 & $1(2)$ & & \\
\hline
\end{tabular}

Nijedan bolesnik nije imao vrednost ECLAM 0 iako su bili u grupi bez aktivnosti. Visoku vrednost 6-8 imalo je 4 novootkrivena lupusa. Prosečna vrednost 4,5.

Na osnovu aktivnosti bolesti (ECLAM) pacijenti su podeljeni u četiri grupe:

1. grupa bez aktivnosti $0-2,0$

2. blage aktivnosti $2,1-4,0$

3. umerene aktivnosti $4,1-6,0 \mathrm{i}$

4. visoke aktivnosti $6,1+\ldots$ 


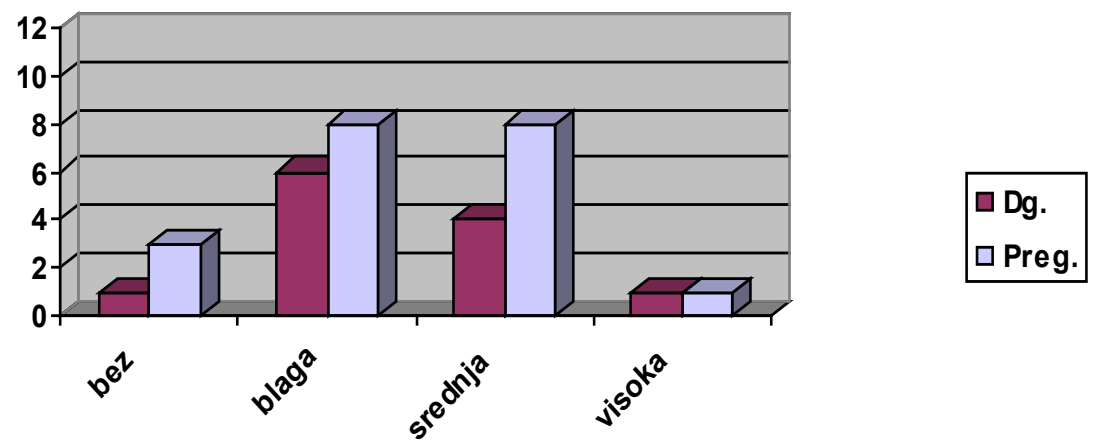

Ispoljavanje hematoloških manifestacija pri postavljanju Dg:

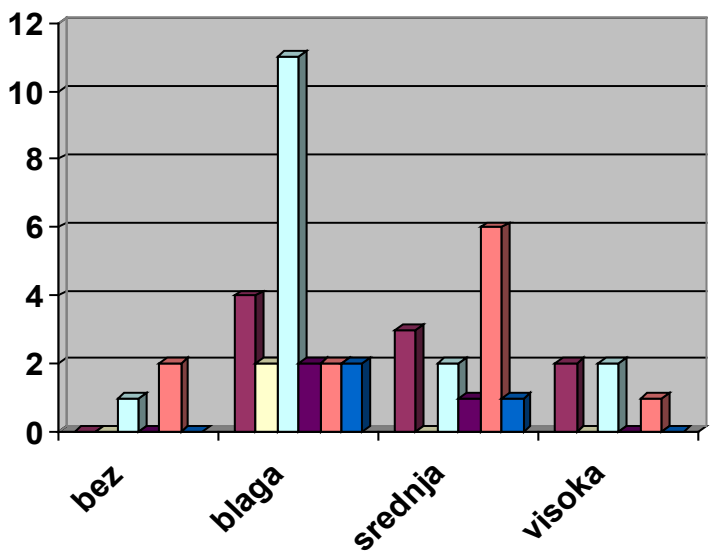

\begin{tabular}{|l|}
\hline nehem an \\
$\square$ hem an \\
$\square$ leukop \\
$\square$ tromboc \\
$\square$ nehem+leukop \\
$\square$ leukop+tromb \\
\hline
\end{tabular}

Najčešća hematološka manifestacija u grupi bolesnika sa blagom aktivnošću bolesti je leukocitopenija, dok je u grupi bolesnika sa srednjom aktivnošću bolesti najispoljenija manifestacija bila nehemolizna anemija sa leukocitopenijom.

\section{Ispoljavanje hematoloških manifestacija pri pregledu}
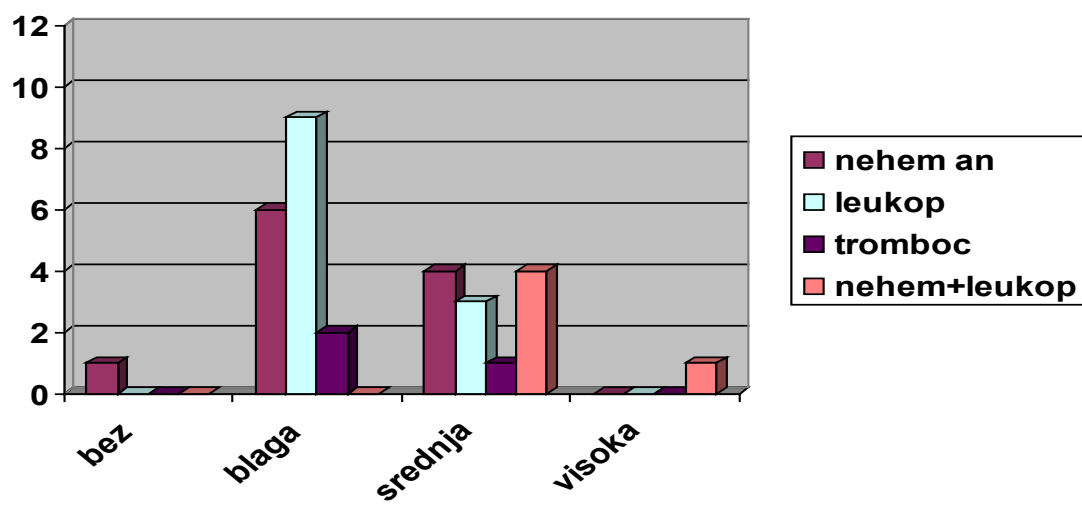
Najčešća hematološka manifestacija u grupi sa blagom aktivnošću bolesti je leukocitopenija, kao i nehemolizna anemija.

Bubrežne lezije pri postavljanju Dg i pri pregledu

$\begin{array}{lrcrc} & \text { ne } & \text { da } & \text { ne } & \text { da } \\ \text { bez akt. } & 4 & 1 & 4 & 3 \\ \text { blaga } & 25 & 6 & 30 & 8 \\ \text { srednja } & 12 & 4 & 5 & 8 \\ \text { visoka } & 5 & 1 & 1 & 1\end{array}$

Pojava bubrežne lezije je bila najviše u porastu u grupi sa srednjom aktivnošću, Hi kvadrat test je pri postavljanju Dg iznosio 0,965 a pri pregledu 0,359 , u oba slučaja je $\mathrm{p}>0,05$ pa promena nije statistički značajna.

\section{Grafikon bubrežne lezije pri postavljanju Dg i pri pregledu}

br. bolesnika

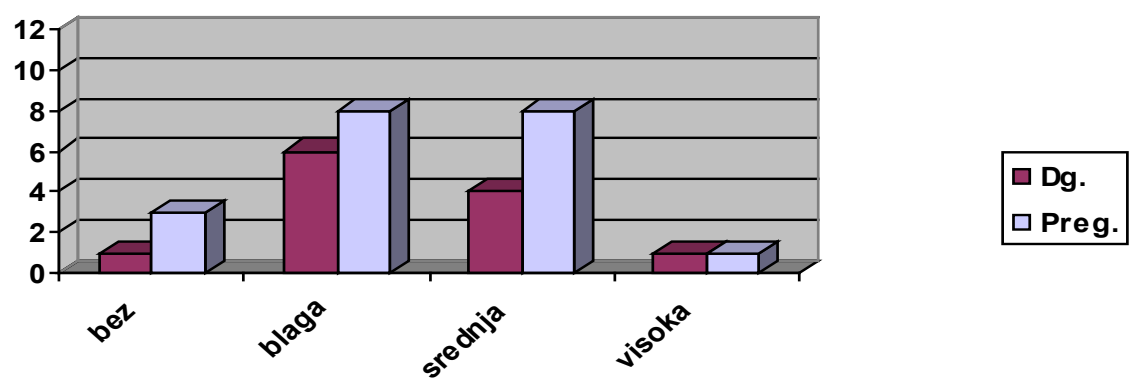

CNS manifestacije u grupama bolesnika podeljenih prema vrednostima ECLAM pri postavljanju Dg i pri pregledu

$\begin{array}{lrlrl} & \text { ne } & \text { da } & \text { ne } & \text { da } \\ \text { bez aktiv. } & 6 & 0 & 7 & 0 \\ \text { blaga } & 28 & 4 & 32 & 6 \\ \text { srednja } & 13 & 3 & 9 & 4 \\ \text { visoka } & 4 & 2 & 2 & 0\end{array}$

Hi kvadrat, $p>0,05$ u oba slučaja, pojava nije statistički značajna.

Lezija CNS-a je registrovana kod 12 bolesnika, što iznosi 15\%, najzastupljenija u grupi sa blagom aktivnošću bolesti pri pregledu, što pokazuje sledeći grafikon. 


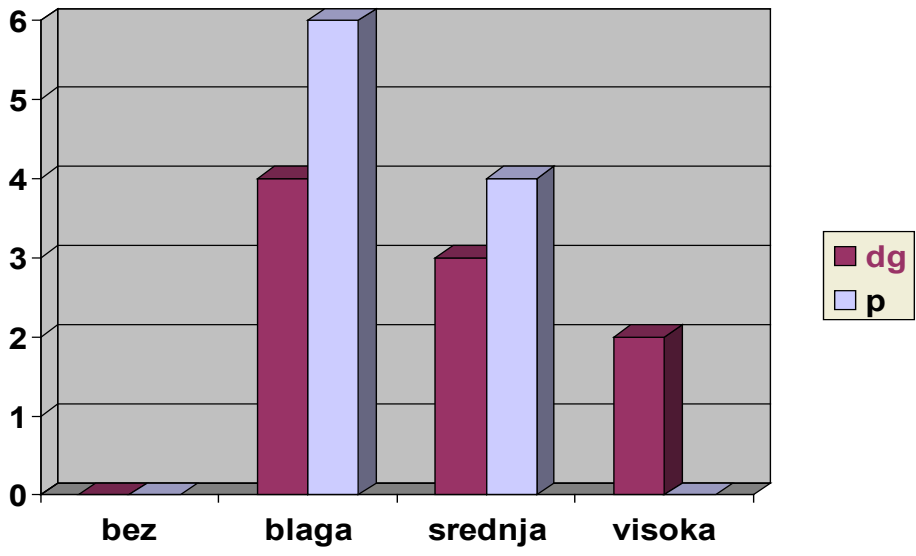

Pozitivna ANA At u grupama bolesnika podeljenih prema aktivnosti bolesti

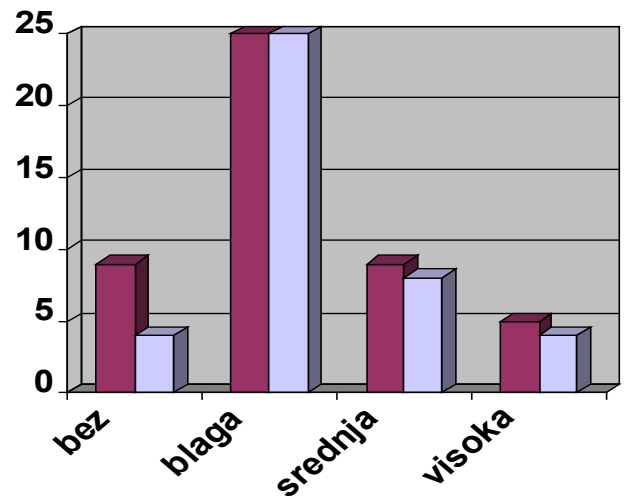

$\square$ Dg.

$\square$ Preg.

Visok titar ANA antitela je bio najviše u grupi bolesnika sa blagom aktivnošću bolesti, održavao se tokom trajanja bolesti, čak bio u porastu. Nije bilo razlike u distribuciji titra ANA At u vreme postavljanja Dg i pri pregledu u odnosu na aktivnost bolesti.

U grupi bolesnika sa blagom aktivnošću bolesti visok titar antitela je tokom trajanja bolesti bio kod većeg broja bolesnika, a sa srednjom aktivnošću broj pacijenata sa visokim titrom At je opao.

U grupi visokoevolutivnih bolesnika titar ANA At se održavao kod većeg broja bolesnika, ali je kod jednog bio negativan pri postavljanju Dg i pri pregledu.

Visok titar je bio prisutan kod jednog bolesnika pri pregledu iako je bolest bila bez evolutivnosti, što znači da autoimuni proces uvek postoji iako nema kliničkog ispoljavanja. 


\section{Zaključci}

Najveći broj bolesnika je u vreme pregleda imao blagu aktivnost bolesti iskazanu ECLAM indexom.

U vreme pregleda preko $80 \%$ bolesnika je imalo vrlo mali indeks oštećenja $(16,7 \%-0,43,3 \%-1,21,7 \%-2)$.

U periodu praćenja nije bilo smrtnih ishoda.

\section{Reference}

1. Gladman DD, Inbanez D, Urowitz MB. Systemic Lupus Erythematosus Diseas Activity Index 2000. J Rheumatol 2002; 29: 288-91.

2. Gladman DD, Urowitz MB. Clinical Features, Systzemic Lupus Erhytematosus, Hochberg MC, Silmon AJ, Smole JS at all, 1356-1373, Mosby, Edinburg, London, 2003.

3. Hanly JG. Disease activity, cumulative damage and quality of life in systemic lupus erythematosus: results of a cross-sectional study. Lupus 1997; 6: 243-47.

4. DCruz D, Hughes GRV. Lupus and the nervous system. Lupus 2003; 12: 871.

5. Gajić G. Procena vrednosti više indeksa aktivnosti u sistemskom eritemskom lupusu. Magistarski rad, Medicinski fakultet, Beograd 2003. 